\title{
Litigation for Health Technology Accessibility: A Tool for Inequality? Reflections Based on Case Study Analysis
}

\author{
Gustavo H Marin ${ }^{1,2 *}$, Lupe Marin ${ }^{1,3}$, Daniel Agüero ${ }^{4}$, Gina Marin ${ }^{1}$, Mariana Pagnotta ${ }^{1}$ and Luis Blanco $^{1}$ \\ ${ }^{1}$ Department of Medical Science, National University of La Plata, Argentina \\ ${ }^{2}$ CONICET: National Scientific and Technical Research Council, Argentina \\ ${ }^{3}$ CIC: Scientific Research Committee, Buenos Aires, Argentina \\ ${ }^{4}$ National University of Arturo Jauretche, Florencio Varela, Argentina
}

Correspondence should be addressed to Gustavo Marin, gmarin2009@gmail.com

Received: July 25, 2020; Accepted: August 05, 2020; Published: August 12, 2020

\begin{abstract}
$\underline{\text { ABSTRACT }}$
INTRODUCTION

The objective of this work is to analyze the characteristics of litigation for access to health's goods and services in the Social Health Insurance (SHI) of Buenos Aires, Argentina.
\end{abstract}

\section{METHOD}

Descriptive study with analytical stage, performed in SHI, analyzing litigation done by beneficiaries along 15-years period to obtain goods or service from health managers. Variables explored were: Reason for litigation, delay time in case resolution, final result of judicial sentence, judges, lawyers and intervening professionals, income level of beneficiaries who started the litigation.

\section{RESULT}

825 cases were analyzed during the study period according the method described. Demands increased $29.2 \pm \%$ per year. Medicines were the goods that most requested legal protection resources (32.5\%). 51.9\% of these litigations were due to medicines that have less than 24 months of registration by the National Regulatory Agency. The average delay for the final resolution of the procedure was 3.7 months. Judge's sentence was favorable to the beneficiaries in 97.4\%. Although there are 27 judicial departments and many courts in each one; cases were concentrated in $47.4 \%$ only 2 very few courts. Litigation cases promoted by 112 out of the 15000 doctors that provides services to the SHI. In $73.7 \%$ of the cases, beneficiaries that litigated had a salary that exceed 4 times the minimum wage, and only $3.2 \%$ of them had low income.

\section{CONCLUSION}

We show how legal appeals might be working as an inverse strategy to the one desired, transferring collective resources belonging to the entire population, towards an specific demand from the most economically wealthy sector of society. As

Citation: Gustavo Marin, Litigation for Health Technology accessibility: A Tool for Inequality? Reflections based on Case Study Analy sis. J Clin Cases Rep 3(S3): 14-19.

2582-0435/@ 2020 The Authors. Published by TRIDHA Scholars. 
http://www.tridhas cholars .org | October-2020

long as access to health care litigation maintains its current individualistic pattern, it will hardly be able to develop its full potential to guarantee effective respect for the collective right to access to goods that beneficiary the whole community.

\section{KEYWORDS}

Litigation; Health; Technologies; Medicines; Inequality

\section{INTRODUCTION}

Judicial litigation in relation to health has severity increased during the last decades throughout the world, specifically in low or lower middle income territories like most countries Latin American [1].

Many South American, Central American and Caribbean countries have chronic financial problems in order to guarantee their entire population basic services such as access to drinking water, sewers, and decent housing [2].

However, it is observed that governments, responding to legal actions [3], permanently transfer resources to guarantee $4^{\text {th }}$ generation rights, such as "High Cost/Price" medicines [4] to a certain sector of the population (mostly people that have the educational and economic tools to hire a lawyer); delaying the transfer of resources to address $2^{\text {nd }}$ generation rights such as food, housing, education or basic health services.

There is no doubt that there is a substantial increase of litigation in Latin America, increasing prosecutions and redistributing funds to attend new needs of certain sectors of the population. These "new needs" are related to the production of new health technologies, which grow very fast, and appear aggressively in the health market, stressing the budgets allocated to health. The cost of these new goods makes it clear that they could not be provided to everyone [5].

Particularly in Argentina, the health structure is divided into 3 sub-sectors: The public (financed and provided by national, provincial and municipal institutions), Social insurance (financed by union, provincial or national 
fee is variable, although an advance payment is usually requested from the petitioner or a payment in installments - even though the costs could finally be paid by the defendant health Institution according to the type of coverage of the petitioner. It is not well studied though, what type of population accesses to this type of legal resources, and if that initial payment required, excludes economically vulnerable populations from this judicial strategy.

The objective of this work is to analyze the characteristics of litigation for access to health's goods and services in the Social Health Insurance (SHI) of public sector workers of Buenos Aires, Argentina.

\section{METHODOLOGY}

Study Type

Descriptive with analytical stage.

\section{Universe}

Legal appeal resources initiated by affiliates of the Provincial Social Health insurance (Social Insurance for public sector workers) in the last 15-years, Buenos Aires, Argentina.

\section{Period of Study}

$01 / 01 / 2003-31 / 12 / 2018$

\section{Sample/Sample Size}

For calculating the sample size and the sample it was used platform Java ${ }^{\mathrm{TM}}$, Standard Edition 7, Development Kit. Cases selected of each year were included by a simple random way among the universe of all litigation cases presented against the SS entity, in Buenos Aires province, Argentina.

\section{Variables Analyzed}

Reason for litigation, year of initiation, delay time in case resolution, final result of judicial sentence, local town of beneficiaries, location of courts; judges, lawyers and intervening professionals; income level of the beneficiaries who started the litigation.

\section{Statistical Analysis}

Quantitative variables were presented as mean values, and minimum and maximum $95 \%$ confidence interval, while those without normal distribution were presented in median. The qualitative variables were presented in percentages for each parameter explored.

\section{Ethical Aspects}

All data on beneficiaries, prescribers; judges, lawyers, doctors, courts were initially coded by SHI to avoid nominal identification. The Social Health Insurance Entity only provided these coded data; none of the researchers had access to the identification of the people involved in these cases.

\section{RESULTS}

825 cases of judicial protection were randomly selected during the study period according the method described. The number of appeal on the ground of unconstitutionality increased on average by $29.2 \pm \%$ each year.

Medicines were the goods responsible for most of the requested protection legal resources presented by beneficiaries in judiciary courts $(32.5 \%)$ (Table 1$)$.

\begin{tabular}{|c|c|}
\hline Main Reason for Appeal & Percentage \\
\hline Medicines & $32.16 \%$ \\
\hline Home care & $16.75 \%$ \\
\hline Disability & $16.50 \%$ \\
\hline Assisted Fertilization & $13.59 \%$ \\
\hline Devices & $7.70 \%$ \\
\hline Practices & $5.70 \%$ \\
\hline Prosthesis & $5.34 \%$ \\
\hline Addictions & $4.37 \%$ \\
\hline Psychology & $3.15 \%$ \\
\hline Odontology & $0.36 \%$ \\
\hline
\end{tabular}

Table 1: Reasons for the petition for the appeal on the ground of unconstitutionality.

The analysis of medicines as requested goods establishes that $54.7 \%$ of them were not included in the regular 
Provincial Social Insurance treatment protocols or in other official therapeutic protocols (Table 2) and most than half of these litigations were due to medicines that have less than 24 months of registration by ANMAT (National Regulatory Agency).

\begin{tabular}{|l|r|}
\hline Medicines & Percentage \\
\hline Medications not included in SHI protocols & $54.70 \%$ \\
\hline Medications included in protocol but that but that generated protection for rejection of audit & $45.30 \%$ \\
\hline High cost drugs among those NOT included in protocols, and registered by the regulatory agency with less than 2 years by the time of the request & $51.90 \%$ \\
\hline High cost drugs of total drugs for diseases considered rare & $29.80 \%$ \\
\hline
\end{tabular}

Table 2: Judicial Appeals based in medicines.

\section{Appeal Process Procedure}

In all the cases explored, firstly, a court order was requested to is sue a prompt dispatch. Once the claim was presented and after it was admitted, the judge requested that within 5 days the State Social Insurance administration be issued on the causes of the alleged delay. After this requirement was answered or the deadline expired (which occurred in 38\%), in all cases the judge resolved and issued an order for the Social Health Insurance administrative authority to comply with the beneficiary's request.

The average delay for the final resolution of the procedure was 3.7 months (range 1 month - 27 months), while $16.3 \%$ were resolved in less than 30 days.

The judge's sentence was favorable to the beneficiaries in $97.4 \%$ and favorable to Social Health Insurance entity in $2.6 \%$.

Although there are 27 judicial departments in the province of Buenos Aires, $47.4 \%$ of the cases were initiated and registered in 2 of these departments. At the same time, within each judicial department, the cases were concentrated in a few courts (for example, in Bahía Blanca judicial department there are 8 civil-commercial courts and 3 guarantees courts available, however $76.9 \%$ of the cases were requested from one only court.
The litigation cases were signed only by 112 doctors while the health professionals provide services to the Social Insurance are more than 15.000 .

$73.7 \%$ of the affiliates who started a litigation case had a salary that exceed 4 times the minimum living and mobile salary at the time the judicial appeal began; and $23.1 \%$ had a salary above 2 times the minimum wage. The general average was 4.12 times over the minimum wage. In other words, the vast majority of those affiliates who used the litigation strategy belonged to middle/upper class of the Argentine society.

\section{DISCUSSION}

This work is based on a case study of the Provincial Social Health Insurance, which gives coverage to public estate workers.

It is shown that medicines are the main cause of litigation in the health system. The exponential growth of new health technologies, especially medicines, put health budgets (like SHI) at risk, and expose governments to the dilemma of choosing between attending to individual specific rights, or leaving behind some collective rights that might impact positively in the level of health's population.

Litigation is a protective escape valve for individual rights in particular situations in which it is considered 
that vital care has not being accessed, however, since these judge's sentences are the last authorized word of the judicial system, they may serve as a precedent for future decisions in others the national, provincial or local courts of the countries, where the situations are not exactly the same.

It must be considered that the legal and social actors involved in litigation have their particularities and differences and they do not always have the best information available to make these type of decisions. The ways in which judges interpret the laws, could be involuntarily functional to those other actors (doctors, lawyers, pharmaceutical industry) that have economic interests beyond the achievement of the benefit for the petitioner. One situation that might reflects this point in our study it is the preference of lawyers, and beneficiaries to choose some court offices, to present their claims.

Undoubtedly, the legal appeal is in theory, a valid judicial tool to protect those individuals who consider that they are denied to a legitimate right. In almost all the cases, as we observed in this study, the judges rule in favor of the beneficiaries since they consider that their health is at risk.

However, far from being an equity tool, the legal appeals might be working as an inverse strategy to the one desired, transferring collective resources belonging to the entire population, towards an specific demand from the most economically wealthy sector of society. In this case, only $3.2 \%$ of the beneficiaries that received a favorable legal sentence, belonged to a socially vulnerable low income class. This situation would seem to be a kind of "Robin Hood in reverse" since collective goods and services are being taken from the poorest to meet the specific and specific needs of the richest.
Noteworthy there were no demands by patients with hypertension against Social health Insurance entity, to cover $100 \%$ of the value of antihypertensive medicines, (currently the average coverage is $40 \%$ ), knowing that the lack of access to these drugs will inevitably lead to a heart attack, stroke, or death in the future. The answer is simple, no one lobbies for this type of medicine that are low-priced in the market and because producers and marketers know that they will still receive the money of these goods, since they have an achievable value for the beneficiaries' pockets, to pay the percentage uncovered by the insurance.

For these reasons, we consider that these dilemmas cannot be exclusively resolved in the legal field. The solution must be based on an in-depth scientific analys is that could informs which goods and services have a favorable impact on health's population and for which it will be worth paying.

\section{CONCLUSSION}

We show in this study how legal demands and judicial litigation might be working as an inverse strategy to the one desired, transferring collective resources belonging to the entire population, towards an specific demand from the most economically wealthy sector of society. As long as access to health care litigation maintains its current individualistic pattern, it will hardly be able to develop its full potential to guarantee effective respect for the collective right to access to goods that beneficiary the whole community.

\section{CONFLICTS OF INTEREST}

Authors declare no conflict of interest.

\section{FUNDING STATEMENT}

Authors state the research and publication of their article was funded by the national University of la PlataCONICET, Argentina. 


\section{REFERENCES}

1. Reveiz L, Chapman E, Torres R, et al. (2013) Right-to-health litigation in three Latin American countries: A systematic literature review. Revista Panamericana de Salud Pública 33(3): 213-223.

2. Rojas Aravena F (2011) Iberoamerica: Different perspectives, different paths for shared goals, well-being and development. FLACSO, $1^{\text {a }}$ ed. San Jose, CR.

3. Perehudoff SK, Toebes B, Hogerzeil H (2016) Essential medicines in national constitutions: Progress since 2008. Health and Human Rights 18(1): 141.

4. Marin GH, Polach MA (2011) Costly drugs: Analysis and proposals for the Mercosur countries. Pan American Journal of Public Health 30(2): 167-176.

5. Vidal J, Di Fabio JL (2017) Judicial recourse and access to health technologies: Opportunities and risks. Revista Panamericana de Salud Publica 41(8): e137.

6. Belló M, Becerril-Montekio VM (2011) The health system of Argentina. Salud Pública de México 53(2): 96-109.

7. Belmartino S (2002) Equity issues in health care reform in Argentina. Cadernos de Saude Publica 18(4): 1067-1076.

8. PEN (1995) Decreto 495/02 Programa Médico Obligatorio. Boletín Oficial, Argentina. 